\title{
Patterns of change of mean wind velocity maximums in Krasnodar Krai from the beginning of anemometric measurements
}

\author{
Vladimir Pochinok ${ }^{1}$, Murat Tamov ${ }^{1, *}$, and Andrey Aksenov ${ }^{2}$ \\ ${ }^{1}$ Kuban State Technological University, Institute of Construction and Transport Infrastructure, \\ 350072 Moskovskaya Street, 2, Krasnodar, Russia \\ ${ }^{2}$ STRABAG ZAO, 350049 Turgeneva Street, 83, Krasnodar, Russia
}

\begin{abstract}
Paper addresses maximum annual values of mean wind velocity in all plain and piedmont regions of Krasnodar Krai, which were used as the basis for establishing wind loads on buildings in local code SNKK "Loads and Actions. Snow Loads and Wind Actions". Research employs time series of anemometric measurements of wind velocities from the beginning of 1970s to 2012 extended by 13 years as compared to the time series used for developing this code. Inversion criterion was employed for assessing the significance of the linear trend of wind velocity maximums. Assessment made for the data of 29 meteorological stations showed that significant trend of increase of wind velocity with the high level of statistical certainty is present only in two cases. In half of the rest cases trend is descending, in another half trend is statistically insignificant as well as mostly descending. Combined analysis of time series of vane and anemometric mean wind velocity measurements over 1945-2012 demonstrated one period of significant increase of wind velocities in 1966 - 1977 and sustained decrease of these velocities in $1979-2012$. It is shown that the database of 10 minutes mean wind velocities used for development of SNKK in 2000 does not underestimate wind pressure as compared to the values observed up to the present time.
\end{abstract}

\section{Introduction}

Over last two decades global warming is widely considered to be of the most important problems facing mankind which also among others affects Krasnodar Krai [1]. According to forecast of Roshydromet [2] and Intergovernmental Panel on Climate Change [3] rise of temperature in European part of Russia will be larger than average on the land of Northern Hemisphere, and only in the North Caucasus it will not exceed average changes. Rise of global and regional temperatures may come with change of atmospheric activity with ambiguous patterns of maximum annual wind velocities.

Report of Roshydromet [2] is focused on construction and transport and regards following as possible consequences of global warming for Russia: alteration of parameters

\footnotetext{
* Corresponding author: murat.tamov@gmail.com
} 
of heating season, rising of thermal efficiency of existing buildings and energy usage reduction in wintertime, concerns about overheat of buildings in warm period of the year and heavy increase of energy usage index for cooling of buildings in Southern Federal District, accelerated deterioration of building envelope due to increase in the number of freeze-thaw cycles, etc. At the same time report does not consider the issue of possible change of wind loads on buildings.

The aim of this paper is to assess the patterns of change of mean wind velocities and wind loads in Krasnodar Krai over 1945-2012, including the analysis for possible considerable deviations from the values adopted in the local code for loads and actions. It was approximately since 1950 when first changes in many extreme climate and meteorological phenomena began to appear. In mid-1970s this effect became more evident. Wind velocity measurement data for the research was provided by Krasnodar center of hydrometeorology and environment monitoring.

Until the early 1970 s velocity measurements were made with Wild's vane averaged over 2 minutes interval. In subsequent years rather fast transition was made in Russia to wind velocity measurements with anemorumbometers averaged over 10 minutes interval and accompanied by doubling of daily measurements. The data employed in the research comprised measurements of both types from 31 meteorological stations uniformly spread throughout plain, piedmont and seacoast regions of Krasnodar Krai. Such measurements are not carried out in high mountain area.

\section{Research justification}

At present time maximum annual values of 10 minutes mean anemometric wind velocity are used as a fundamental value for design values of wind loads on buildings in codes of all countries. For this purpose results of long-term meteorological observations are employed joined into continuous time series. Statistical parameters of these series vary. Characteristic and design values of wind velocity calculated with a specified probability on this basis and converted into wind pressure are used for zoning and development of wind load maps for the design codes.

These maps are supposed to predict wind loads on buildings designed for use in subsequent decades. By doing so, by default, it is assumed that in the future atmosphere circulation pattern will remain as it was before. That is, hypothesis of climate permanence is postulated in each geographical location.

The purpose of this paper is to assess the trend of regular change of maximum annual mean velocity values on the basis of the available records. Time series of anemometric measurements of wind velocity over 1965-2012 from 29 meteorological stations located in Krasnodar Krai are used as a background for this assessment. The average number of years of meteorological observations is 37 ranging from 32 to 48 depending on the date of replacement of Wild's vane by anemorumbometers M-63M. Length of the time series $N>30$ considered in this research is quite sufficient for adequate analysis of statistical data.

Based on 1965-1999 data statistical parameters of velocity pressure were determined in all inhabited localities where meteorological observations were carried out. The results of this work evolved into local building code SNKK 20-303-2002 [4]. Methodology of development of this code is elaborated in the works of Pochinok et al. [5, 6].

Trend is a pattern describing a general long-term tendency in variations of time series indices. It is usually assumed that any of observed values $z$ may be presented as the sum of two terms. One of them is $F$ which may be regarded as nonrandom function of coordinates, and another one $\varphi$ - as a random function $z(x)=F(x)+\varphi(x)$. With that, random component $\varphi(x)$ being a function of multiple independent factors is assumed to be normally distributed. 
With the problem of trend detection two tasks arise: identification of general tendency in changes of character of $z$ and isolation of the local component as alternating deviations from trend. Time dependencies of the factor may take different forms. They are therefore described by various functions: linear, exponential, power, polynomial with different degrees, etc. So far possible explicit dependence or correlation between trends of wind velocity and rise of average atmospheric temperature remains unclear. Taking these facts into account in this research the simplest working hypothesis was assumed for analysis linear trend of maximum annual velocities. Similar approach was used in the previous works of the authors [7].

\section{Assessment of trend significance of wind velocities by inversion criterion}

Inversion criterion [8] is considered to be the most effective index of trend significance. Inversion criterion is nonparametric, and therefore distribution function of random components $x_{\mathrm{i}}$ does not have effect on allocation of sampling functions. This test has high strength towards linear trend [17]. It also allows avoiding any assumptions concerning distribution function of examined data.

In combinatorics inversion refers to disturbing the normal order of two elements in permutation regardless of whether these two elements stand close or are separated from each other by some elements. For our purposes let us consider sequence of $N$ observations of random variable $x_{i}(i=1,2,3 \ldots N)$. In our case these are maximum annual values of 10 minutes mean anemometric wind velocity in strict chronological order. The number of times when in increasing sequence of values $x_{\mathrm{i}}$ inequality $x_{i}>x_{j}$ for $i<j$ is true is counted. Each of these inequalities is called inversion. Similarly by definition in monotonically decreasing sequence for inversion to occur inequality $x_{i}<x_{j}$ must be true. The following discussion is valid for both cases.

Let $A$ stand for the total number of inversions. Formally $A$ is calculated as follows. For set of observations $x_{1}, x_{2}, \ldots x_{N}$

$$
h_{i j}=\left\{\begin{array}{l}
1, x_{i}>x_{j} \\
0, x_{i} \leq x_{j}
\end{array},\right.
$$

Then

$$
A_{1}=\sum_{j=2}^{N} h_{1 j}, \quad A_{2}=\sum_{j=3}^{N} h_{2 j}, \quad A_{3}=\sum_{j=4}^{N} h_{3 j} .
$$

Total number of inversions for all initial compared values $x_{1}, x_{2}, \ldots x_{N-1}$ will be

$$
A=\sum_{j=1}^{N-1} A_{i}
$$

If the sequence of $N$ observations consists of independent outcomes of one and the same random value, number of inversions is a random variable $A$ with a mean value $\mu_{A}$ and variance $\sigma_{A}^{2}$ :

$$
\mu_{A}=\frac{N(N-1)}{4}
$$




$$
\sigma_{A}^{2}=\frac{2 N^{3}+3 N^{2}-5 N}{72}=\frac{N(2 N+5)(N-1)}{72} .
$$

Let us check the trend in the series of $N=41$ observations of maximum values of 10 minutes mean wind velocity over 1972 - 2012 for Novorossiysk with the significance level $\alpha=0.05$ (commonly used value for such problems). This city is picked for the analysis for it is here of all European part of Russia where the highest wind velocities in winter period take place (bora). Similar worked example can be found in [16].

Let the working hypothesis be that observations are independent outcomes of random value $x=S$, i.e. there is no trend. Acceptance region of this hypothesis takes the form of

$$
\left[A_{41,1-\alpha / 2}<A<A_{41, \alpha / 2}\right] \text {. }
$$

Calculation of total number of inversions with equation (3) gives $A=552$. Expected value of number of inversions calculated with (4) is $\mu_{A}=410$. Standard deviation is a square root of variance (5) equal to $\sigma_{\mathrm{A}}=44.5$. For $N=45>35$ and confidence level 0.95 fractile of Student's $t$-criterion may be taken as $t=2.01$. Then range of $A$ for significance level $\alpha=0.05$ from (6) is

$$
\left[A_{41,1-\alpha / 2} ; A_{41, \alpha / 2}\right]=\mu_{A} \pm t \times \sigma_{A}=410 \pm 2.01 \times 44.5=321 \ldots 499 \text {. }
$$

Total number of inversions $\mathrm{A}=552$ does not fall into this range. Thus, for Novorossiysk there is a significant descending trend of wind velocity.

Similar calculations made for 29 meteorological stations showed that significant trend of wind velocity growth with a certainty 0.95 is present only in Psebay and Timashyovsk. In half of the rest cases trend is descending, in another half trend is statistically insignificant as well as mostly descending. Results of these calculations are presented in table 1 .

For inhabited localities with descending trend the Pearson linear correlation coefficient $R$ varies within a range from 0.57 (Kanevskaya) to 0.84 (Primorsko-Akhtarsk). In half of the cases correlation is significant on the Cheddok's scale, in the same number of cases it is high (fig. 1). For Psebay and Timashyovsk with ascending trend $R$ is equal to 0.56 and 0.6 accordingly, i.e. correlation is significant. For inhabited localities with insignificant trend correlation is feebly marked - the values of $R$ lie within a range from 0.04 to 0.49 and correspond to slight and moderate level of correlation, mostly slight.

Standards [11] and [12] say, that "during development of national or regional maps ... a set of considered annual peak values can possess positive or negative trend. The evaluation of possible climate change effects has to consider this randomness. Climate change scenarios can provide information on the basic shape of trends which should be considered in the analysis".

For Psebay and Timashyovsk belonging to the wind zone II design wind pressure was reassessed with consideration for established ascending (positive) trend of wind velocity. In SNKK 20-303-2002 for both locations design wind pressure was taken equal to $0.35 \mathrm{kPa}$ with rounding upward, which was less than the upper limit for the zone $0.42 \mathrm{kPa}$. The new precise design value considering the increase of time series length and ascending trend is $0.354 \mathrm{kPa}$ and $0.347 \mathrm{kPa}$ for Psebay and Timashyovsk accordingly. Therefore, in worst cases in terms of design the effect of ascending trend of wind velocity falls within the margin of natural error associated with commonly used rounding during setting the load values. 
Table 1. Confidence interval for significance level $\alpha=0.05$ and total number of inversions $A$ for all compared values of annual maximums of mean wind velocities over 1965-2012.

\begin{tabular}{|c|c|c|c|c|c|c|c|c|}
\hline \multirow{2}{*}{ No } & \multirow{2}{*}{ Location } & \multirow{2}{*}{$\begin{array}{c}\boldsymbol{v}, \\
\mathbf{m} / \mathbf{s}\end{array}$} & \multirow{2}{*}{$\begin{array}{l}\text { Wind } \\
\text { region in } \\
\text { SNKK }\end{array}$} & \multirow{2}{*}{$N$} & \multicolumn{3}{|c|}{ Parameters } & \multirow{2}{*}{ Trend } \\
\hline & & & & & $A_{N, \alpha / 2}$ & $\boldsymbol{A}$ & $A_{N, 1-\alpha / 2}$ & \\
\hline 1 & Belaya Glina & 14.7 & III & 34 & 213 & 380 & 348 & \multirow{14}{*}{ Desc. } \\
\hline 2 & Belorechensk & 12.1 & II & 33 & 199 & 357 & 329 & \\
\hline 3 & Gelendzhik & 20.9 & Special & 36 & 241 & 453 & 389 & \\
\hline 4 & Gor. Klyuch & 11.7 & II & 34 & 213 & 499 & 348 & \\
\hline 5 & Dzhubga & 14.8 & III & 40 & 304 & 611 & 476 & \\
\hline 6 & Yeysk & 17.9 & II & 41 & 321 & 500 & 499 & \\
\hline 7 & Kanevskaya & 9.1 & II & 34 & 213 & 528 & 348 & \\
\hline 8 & Korenovsk & 11.2 & II & 35 & 227 & 572 & 368 & \\
\hline 9 & Krymsk & 16.0 & III & 47 & 431 & 660 & 650 & \\
\hline 10 & Labinsk & 14.5 & II & 32 & 186 & 332 & 310 & \\
\hline 11 & Novorossiysk & 24.3 & Special & 41 & 321 & 552 & 499 & \\
\hline 12 & Pr.-Akhtarsk & 15.8 & III & 41 & 321 & 597 & 499 & \\
\hline 13 & Temryuk & 16.1 & III & 40 & 304 & 607 & 476 & \\
\hline 14 & Tuapse & 15.2 & III & 38 & 272 & 523 & 431 & \\
\hline 15 & Anapa & 20.1 & IV & 39 & 287 & 321 & 454 & \multirow{13}{*}{ Insignif } \\
\hline 16 & Armavir & 16.4 & II & 40 & 304 & 401 & 476 & \\
\hline 17 & Gorniy & 14.8 & II & 34 & 213 & 331 & 348 & \\
\hline 18 & Rrasnodar & 12.2 & III & 40 & 304 & 472 & 476 & \\
\hline 19 & Kropotkin & 8.9 & II & 34 & 213 & 259 & 348 & \\
\hline 20 & Kushchyovskaya & 18.1 & III & 48 & 451 & 634 & 677 & \\
\hline 21 & Maykop & 16.1 & - & 42 & 338 & 475 & 523 & \\
\hline 22 & Otradnaya & 16.8 & II & 33 & 199 & 201 & 329 & \\
\hline 23 & Slavyansk-na-K. & 18.0 & IV & 41 & 321 & 421 & 499 & \\
\hline 24 & Sosyka & 14.2 & II & 34 & 212 & 237 & 349 & \\
\hline 25 & Starominskaya & 12.6 & II & 32 & 186 & 255 & 310 & \\
\hline 26 & Tihoretsck & 12.4 & II & 34 & 213 & 265 & 348 & \\
\hline 27 & Ust-Labinsk & 13.9 & II & 35 & 227 & 335 & 368 & \\
\hline 28 & Psebay & 14.5 & II & 34 & 212 & 168 & 349 & \multirow{2}{*}{ Asc. } \\
\hline 29 & Timashyovsk & 13.8 & II & 33 & 199 & 142 & 329 & \\
\hline
\end{tabular}

Drop of wind velocities is most notable in the first decade of XXI century. In Novorossiysk, for example, surge in 1993 and 1997 was followed two-fold decrease of wind velocities during subsequent 14 years (fig. 1b). Similar pattern is observed for Belorechensk, Gelendzhik, Yeysk, Krymsk, Temryuk and Tuapse. In other inhabited localities such decrease of wind velocities is less pronounced, but in all cases this phenomenon takes place at the same time. 
Figure 2 shows the ratios of maximum annual 10 minutes mean wind velocities to average values over a period 1980-2012 for locations with statistically significant descending trend. The year 1980 was taken as a beginning of the period for the sake of consistency of time series: not all the locations have anemometric measurements prior to this year. The diagrams are normalized in order to provide comparability of results of velocity measurements in three wind zones. All the diagrams clearly demonstrate regular

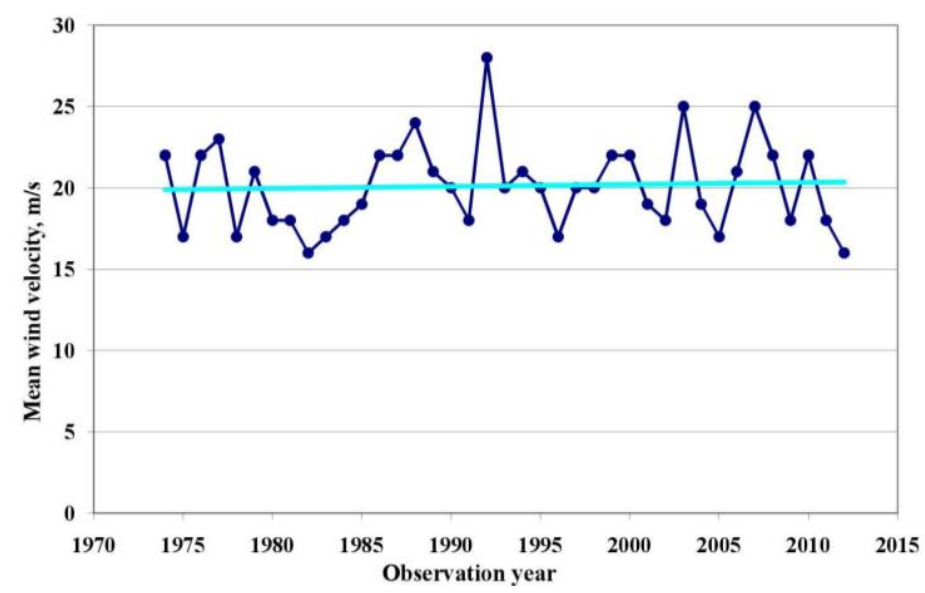

(a) Anapa (insignificant trend)

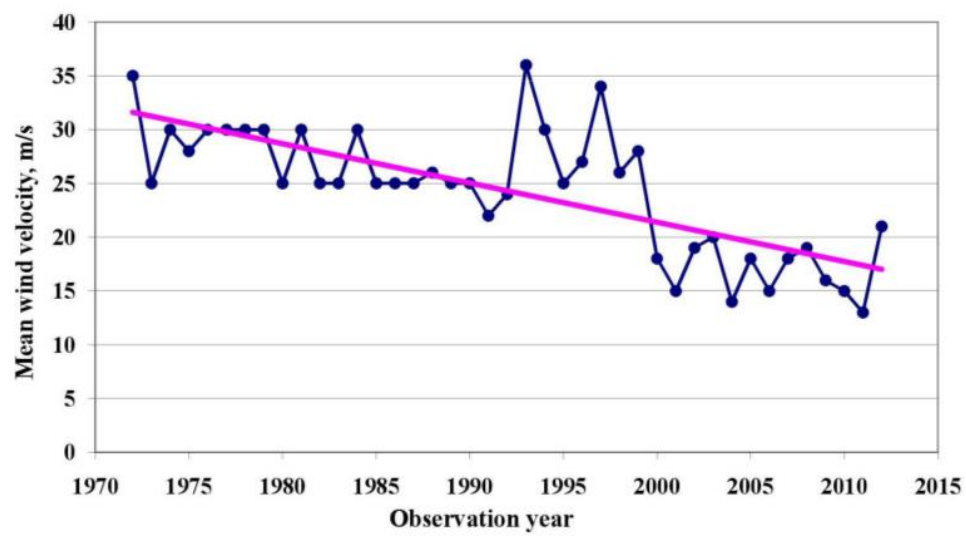

(b) Novorossiysk (descending trend)

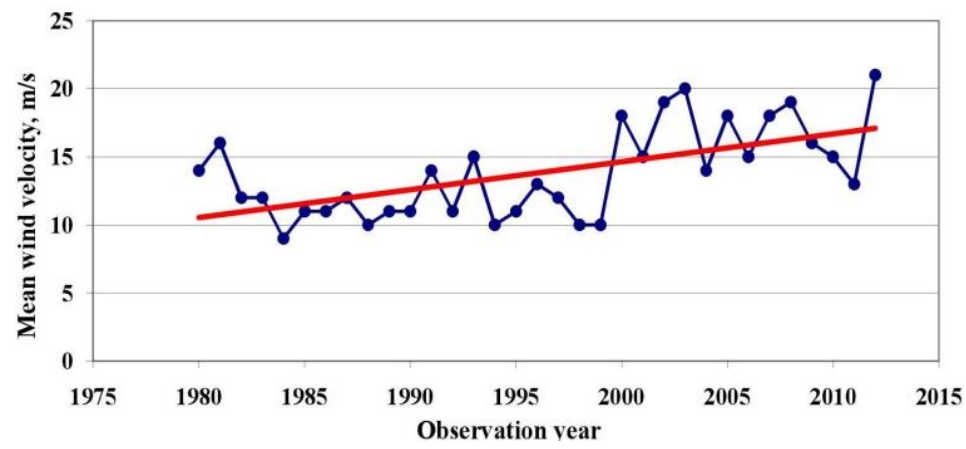

c) Timashyovsk (ascending trend)

Fig. 1. Trend of wind velocities as a non-random time function $F$. 


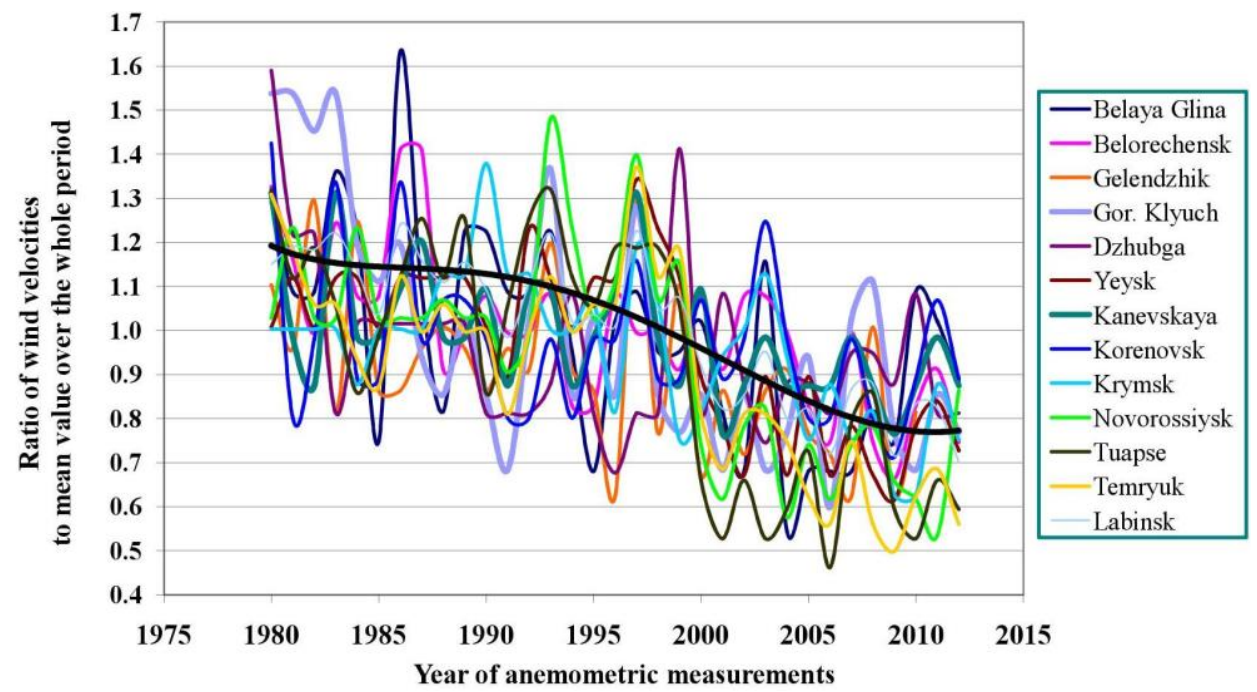

Fig. 2. Ratios of maximum annual mean anemometric wind velocities to average values over a period 1980-2012 and their polynomial trend

difference of aforementioned ratio in the first and second half of observation period. Before 1998 this ratio mostly fell in the range 0.8-1.4, whereas after 1998 - in the range 0.55-1.15. General assessment made by means of polynomial trend in fig. 2 shows a $30 \%$ decrease of mean annual maximums of wind velocities.

Maximum mean anemometric wind velocities were analyzed over 1980-2012. This period has mostly moderate and minimum wind velocities. Unfortunately, there is almost no data available on anemometric wind measurements prior to 1980. For the further analysis available data on 2 minutes vane measurements over 1944-1986 therefore have to be used. The accuracy of this data is certainly lower since Wild's vane has measurements errors due to doubly lower frequency of measurements, different averaging time, tolerances of wind measuring planks, etc. Nevertheless, if combined data from several meteorological stations are considered one can obtain a general picture of systematic variation of wind velocity.

We have at our disposal data from 14 meteorological stations of Krasnodar Krai. In two of these (Dyomin Erik and Kamyshevatskaya) anemometric measurements were not further made. For the remaining twelve stations data over subsequent period were analyzed above.

Figure 3 shows the ratios of maximum annual 2 minutes mean wind velocities to average values over a period of vane measurements and their polynomial trend. In $1960-$ 1976 first slow and then accelerated growth of maximum annual wind velocities took place, which turned into decrease of velocities after 1977.

The data from 1945-2012 was combined using conversion factor found by comparison of available data from simultaneous 11-year wind velocity measurements made with vane and anemometer on 8 meteorological stations. This reduction factor converting 10-minutes mean anemometric velocity into 2-minutes vane velocity is equal to 0.87 . This value is close to the indicative factor 0.92 which was used in 1985 in USSR code for reassessment of wind pressure because of the change of the measurement method and averaging time. In SNiP 2.01.07-85 [12] wind loads from the previous code were multiplied by $0.85=0.92^{2}$ based on the quadratic relation between pressure and velocity of the wind. 
Up to this point only the data from the stations with significant descending trend were considered with this being only the half of available wind velocity measurements. Let us

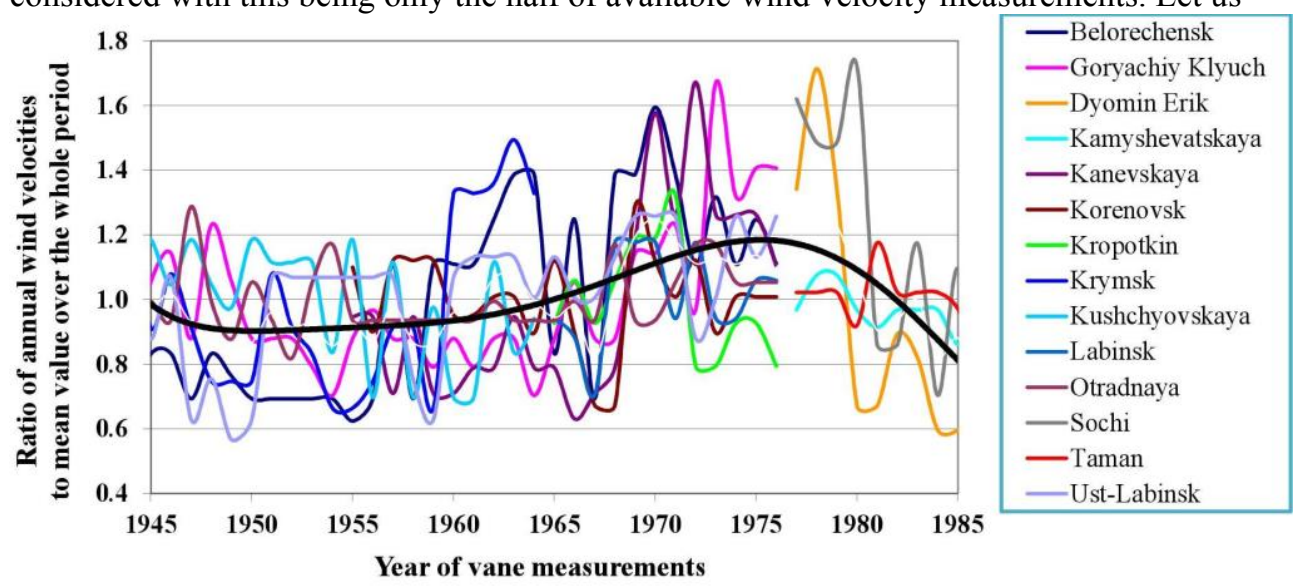

Fig. 3. Ratios of maximum annual mean values of wind velocity to the mean values over the period of vane measurements in 1945-1985 and their polynomial trend

check whether described above patterns will change if we consider all data including those with insignificant trend and even distinctive data from two meteorological stations with significant ascending trend. Given that vane measurements data are only of historical interest, they are not further considered.

Figure 4 shows the diagram of average of 10-minutes mean anemometric wind velocities of all 29 stations normalized by the sample mean for the entire period of measurements.

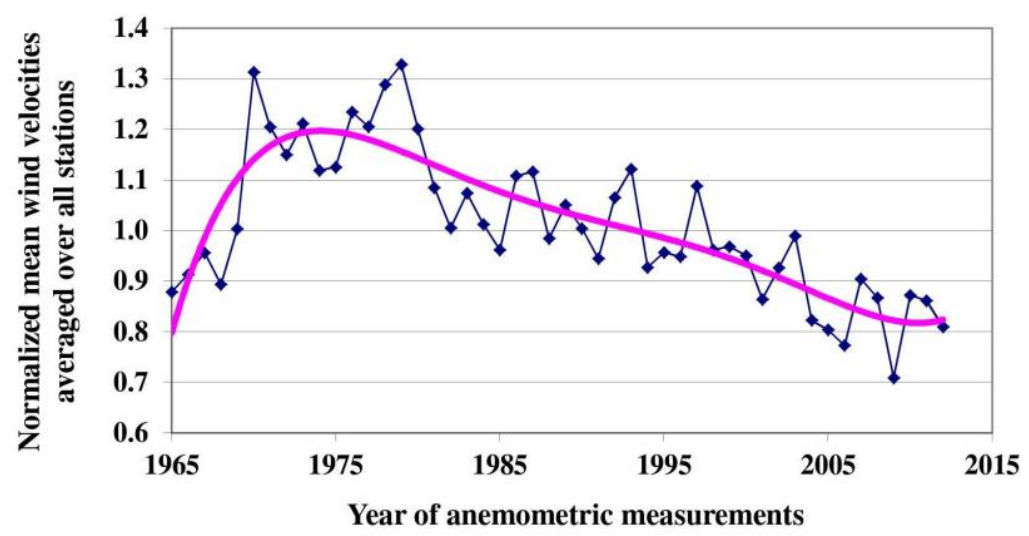

Fig. 4. Normalized maximum annual wind velocities averaged over 29 meteorological stations over a period of anemometric measurements 1965-2012 and their polynomial trend

This diagram has a distinguishable sharp spike of wind velocity growth in 1967-1968. At this time in winter in 1968-1969 in Kuban region well-remembered disastrous dust storms took place, which caused damage of numerous buildings and carried away topsoil across vast agricultural lands.

In the following 34 years (1979-2012) velocities of the strongest winds in Krasnodar Krai almost linearly decreased. By the end of the considered period they became about 1.5 times less, representing nearly $1 \%$ annual decrease. For a short term of several years this change is barely noticeable, but over a period of three decades it becomes significant. 
Medium level of maximum annual mean wind velocities over considered period 19652012 was reached by 2000 . It decreased further up until 2012 . Wind velocity reduced by $16 \%$ as compared to the average values over the entire considered period by 2012 .

Thus, in analyzed time range 1945-2012 one period of growth of maximum mean wind velocities from 1960 till 1977 by about 30\% and 35-year period of their decrease from the reached highest level by about $45 \%$ were conclusively found. By the end of this term wind velocity was equal to $84 \%$ of value averaged over the entire considered period.

\section{Conclusions}

1. Trend analysis of maximum annual mean wind velocities in Krasnodar Krai revealed statistically significant decrease by about $30 \%$ over a period 1979-2012. However, it is not clear how long this trend may last.

2. The database of annual maximum 10 minutes mean wind velocities which was employed for development of local code SNKK 20-303-2002 in 2000 does not underestimate wind pressure as compared to the values observed up to the present time. This conclusion is confirmed by analysis of the time series of wind velocities extended by 13 years from the issue date of this code.

However, it is not conservative to make predictions of further decrease of wind loads over next decades because besides ongoing climate warming many experts consider the opposite tendency possible. Long-term cold snap is anticipated similar to the one that took place in the second half of XVII century during rapid and long-lasting decline of solar activity.

Research [13-15, etc.] show that since the beginning of 23 solar cycle in 1996 Earth is entering a period of low and medium solar cycles which may last some 5-6 solar cycles with total of 50-70 years. In this case atmosphere circulation pattern can change for a long period and another trend pattern of wind velocity is possible. Thus, the possibility of further significant increase of wind velocities in future cannot be completely ruled out because of the changing global natural processes or onset of new abnormal solar cycle similar to the 20th cycle.

\section{References}

1. A. Matveeva Kubanskaya zima [Kuban winter] (2015) Available from: http://kuban24.tv/item/spetsreportaj-kubanskaya-zima-114072

2 Roshydromet Vtoroj ocenochnyj doklad Rosgidrometa ob izmenenijah klimata $i$ ih posledstvijah na territorii Rossijskoj Federacii [Second estimative report of Roshydromet on climate changes and their consequences on territory of Russain Federation] (2014)

3. IPCC Climate change 2013: The physical science basis. Summary for policymakers (2013) Available from: https://www.ipcc.ch/site/assets/uploads/2018/02/ WG1AR5_all_final.pdf

4. KubSTU SNKK 20-303-2002 Nagruzki i vozdejstviya. Vetrovaya i snegovaya nagruzki [Loads and actions. Wind and snow loads] (2003)

5. V. Pochinok, V. Kramskoy, A. Aksenov, Yu. Pochinok, Trudi KubGTU. Nauchniy zhurnal [KubSTU research. Scientific journal] 24, 70-76

6. V. Pochinok, A. Aksenov, Proc. 6th Int. Conf. on Const. in Coastal Resort Areas, 40-43 (SGU, Sochi, 2010)

7. V. Pochinok, M. Tamov, M. Tamov, IOP Conf. Ser. Mater. Sci. Eng. 365 (2018) 
8. J. S. Bendat, A. G. Piersol Random Data: Analysis and Measurement Procedures (Wiley-Interscience, New York, 1986)

9. I. Veretelnikova, B. Lemeshko Obrabotka informacii i matematicheskoe modelirovanie: materialy RNTK [Data analysis and mathematical simulation: RNTK Proc.] 27-38 (SibGUTI, Novosibirsk, 2016)

10. International Organization for Standartization ISO 4355:2013 Bases for design of structures - Determination of snow loads on roofs (ISO, Geneva, 2013)

11. Rosstandart GOST ISO 4355-2016 Osnovy proektirovaniya stroitelnyh konstrukcij. Opredelenie snegovyh nagruzok na pokrytiya. [Bases for design of structures Determination of snow loads on roofs] (Stadartinform, Moscow, 2017)

12. TSNIISK SNiP 2.01.07-85* Nagruzki $i$ vozdeystviya [Loads and actions] (FGUP CPP, Moscow, 2005)

13. V. Ishkov Russ. Annu. Conf. on Solar Physics, 111-114 (Pulkovo Observatory, SaintPetersburg, 2013)

14. J.E. Beckman, T.J. Mahoney ASP Conf. Ser. 153, 212-217 (Astronomical Society of the Pacific, San-Francisco, 1998)

15. E. Popova, V. Zharkova, S. Zharkov Ann. Geophys. 31, 2023-2038 (2013) 